\title{
Trends in depressed mood and suicidal behaviors among female high school students who engaged in physical fighting
}

Janet H. Ford, MPH, PhD; Terrell W. Zollinger, DrPH; Jianjun Zhang, MD, PhD;

Joseph O’Neil, MD, MPH; David R. Nelson, MS; Gregory K. Steele, DrPH, MPH

\begin{abstract}
Objective: Identify prevalence changes in depressed mood/suicidal behaviors among female high school students reporting physical fighting. Methods: This research analyzed the national combined dataset of the Youth Risk Behavior Surveillance (YRBS) cross-sectional surveys from 2001 to 2015. Logistic regression analyzed the time trends. Two multiple logistic regression models were built. Results: A quadratic trend was present with an initial decrease followed by an increase 2009-2015 ( $<<0.001)$. The oddsand severity of depressed mood/suicidal behaviors was greater among female youths with 4 or more fights and for other violent events, which was even greater when accounting for electronic bullying. Conclusions: The odds of depressed mood/suicidal behaviors among female adolescents engaged in physical fighting has been increasing with electronic bullying contributing to polyvictimization..
\end{abstract}

Key Words: Mental Health and Violence, Youth Violence, Violent Offenders

This is the author's manuscript of the article published in final edited form as:

Ford, J. H., Zollinger, T. W., Zhang, J., O’Neil, J., Nelson, D. R., \& Steele, G. K. (2018). Trends in Depressed Mood and Suicidal Behaviors Among Female High School Students Who Engaged in Physical Fighting. Journal of Interpersonal Violence, 0886260518790599. https://doi.org/10.1177/0886260518790599 


\section{INTRODUCTION}

In $2015,40 \%$ of female adolescents reported depressed mood, with $20 \%$ considering or planning a suicide attempt and more than $10 \%$ actually attempting suicide (Kann, 2016). Among female youths ages 15 to 24 years, the rate of suicide in the US has increased by approximately 50\% from 1999 to 2014, and among ages 10 to 14 years the rate has tripled (Curtin, 2016). One of the strongest predictors for suicidal death is the history of a previous suicide attempt (Hawton, 2013). Injuries related to self-harm (all methods) from 2009 through 2013 have also statistically significant increased from approximately 275 per 100,000 in 2009 to 387 per 100,000 in 2013 among female youths 15 to 19 years of age (Bell, 2016).

The risk of depression and suicidality among female adolescents by the age of 18 years, are three-fold higher for those who participate in aggressive behaviors such as physical assault and fighting with a weapon (Deeds, 2007; Lereya, 2015). The annual rate of assault-related injuries treated in US emergency departments among the female adolescent population, from 2009 through 2013 decreased; however, only assaults with a firearm in the age group 10 to 14 years achieved statistical significance (Bell, 2016). The prevalence of physical fighting among female high school students in the U.S. in 2015 was $16.5 \%$, with the highest prevalence among black female students at $25.4 \%$ (Kann, 2016). Female adolescents identify multiple reasons for participating in physical fighting, including: social status or motives, respect, preventive measure for future fights, retaliation, coping, enjoyment or self-defense (Resko, 2016). Despite a significant linear decrease in the prevalence of physical fighting among a national sample of all high school students from $42.5 \%$ in 1991 to $22.6 \%$ in 2015 , geographical disparities were noted, with ranges from $13.9 \%$ to $42.5 \%$ across 19 large urban school districts (Kann, 2016). The 
discrepancies are concerning given that the propensity to act violently is a reflection of chronic exposure to violence or a threatening environment with recurrent distress having the potential to invoke the desire to escape including thoughts of suicide (Giletta, 2016; Wilkins, 2014). Therefore, in addition to the acute risk of physical injuries due to violent aggression, as these adolescents mature into adulthood they are more likely to have multiple suicide attempts, a lethal suicide attempt, persistent psychological conditions, physical comorbidities, violent criminal offenses and behaviors, and socioeconomic challenges such as unemployment (Boots, 2009; GoldmanMellor, 2014; Goldston, 2015).

The increasing prevalence of depressed mood and suicidal behaviors, along with the decrease and variability in physical fighting in the female adolescent population warrants further investigation. Research to date indicates a complex phenomenon between internalizing and externalizing behaviors among youths exposed to violence, therefore a conceptual model for researching trends in depressed mood and/or suicidal behaviors and the relationship with violence is presented in Figure 1. In this framework physical fighting is considered an act of aggression whether or not the individual was the instigator or acting in self-defense. In addition, the model specifically describes time trends in electronic communication over the study period, given the emergence of electronic bullying. Literature supporting the conceptual model, include:

- Adolescent female youths are considered a vulnerable population, given genetic evidence of greater susceptibility to expression of psychological morbidity when exposed to chronic stressors, such as violence (Hankin, 2015). 
- Among female youths with aggressive externalizing behaviors, the risk of suicide attempts is six-times greater among more frequent physical fighters than non-fighters; however, it is important to address bidirectional violence given that over $95 \%$ have also been victims of violence (Lereya, 2015; Swahn, 2013).

- The accumulation of violent exposures and the subsequent psychological adverse outcomes are known to precipitate externalizing behaviors, such as aggression (Ruback, 2014; van der Put, 2015).

- The level of risk for becoming a perpetrator is differential, with greater risk for female youths who are victimized at a young age and exposed to higher frequencies and/or multiple forms of violence (Deeds, 2007; van der Put, 2015).

- Victimized female youths often suffer from internalizing mental health conditions such as depression and suicide, which leaves them at risk of violent re-victimization and progressing to aggressive behaviors; which results in a greater severity and a higher prevalence of mental health conditions than unidirectional violence (Deeds, 2007; Ruback, 2014; Satyanarayan, 2015; Ulloa, 2016).

- Electronic bullying (any kind of aggression perpetrated through technology) has been introduced and emerging, with more than $20 \%$ of female adolescents being exposed, which may be resulting in an increasing risk of poly-victimization, aggressive behaviors and associated morbidity and mortality (Bell, 2016; Boots, 2009; Goldman-Mellor, 2014; Goldston, 2015; Kan, 2016). This conceptual model and the literature facilitated the development of unanswered research questions and informed the study design to address the current gaps in knowledge. 
This research is important, and addresses unique and recent trends in depressed mood and/or suicidal behaviors as related to violent aggression, risks associated with exposure frequency, the role of other risk and protective factors, and the implications of sustaining an injury in need of treatment for an aggressive behavior, with female youths being a specific vulnerable population of interest. In addition, this fills a gap in the scarcity of violence research focused on female adolescents. The National Institutes of Health, Violence Against Women (VAW) Research Report has specifically called for research that addresses the risk of mental health disorders and perpetrating behaviors in this population (Herrman, 2012; NIH, 2011). Overall the need to better understand prevalence time trends associated with poor mental health outcomes among female adolescents that exhibit aggressive behaviors, the associated violent risk factors, polyvictimization, and any changes related to the introduction of electronic bullying are recognized areas in need of more research (Gladden, 2013; Lenhart, 2012; Madden, 2013; Ybarra, 2011).

The main objective of this study was to analyze changes in the prevalence of depressed mood and/or suicidal behaviors among female high school students who reported physical fighting, from 2001 through 2015 in the U.S., a question that has not been addressed in previous research. It was hypothesized that the prevalence of the outcome among physical fighters had increased during this time period, due to more opportunities for polyvictimization given the introduction of electronic bullying. This study was designed to address the following research questions: 1) how has the prevalence of depressed mood/and or suicidal behaviors among physical fighters changed in recent years, 2) what are the associated trends with other violent risk factors, and the need for medical treatment of related injuries 3 ) how does risk change with frequency of physical fighting and the number of other violent exposures, 4) how has the risk of depressed mood and/or suicidal behaviors changed among physical fighters with the introduction of electronic bullying. Addressing the research questions 
of the present study are important given the recent increase in suicide rates among female adolescents, the current and future health of this vulnerable population, and the societal implications.

\section{METHODS}

\section{Participants and Survey Procedures}

Female high school students (grades nine through twelve) enrolled in public and private schools, who participated in the Youth Risk Behavior Surveillance (YRBS) national U.S. survey in the years of 2001 through 2015 were included in this study. Out of the 117,815 total usable questionnaires, 415 were not included in this analysis due to missing data on gender. Of the remaining 117,400 surveys, 57,708 (49.2\%) survey responders self-identified as being female.

The YRBS is administered every two years by the Centers for Disease Control and Prevention (CDC) and began in 1991. Adolescent health risk behaviors associated with social well-being, morbidity, and mortality are monitored using this school-based survey (Brener, 2013). Multiple risk behavior categories are captured, including: unintentional injuries, violence, sexual behaviors, drug and alcohol use, smoking, dietary behaviors, and physical activity. Only minor revisions to the survey have occurred over time (Brener, 2013). The study population is a nationally representative sample of high school students (public and private), with a three-stage cluster sample design using primary geographical sampling units, schools and a random sampling of students in each grade. The CDC designed the survey items and data collection methods to reduce non-response and reporting bias, while also omitting illogical surveys; average response rates are approximately $60 \%$ (Krumpal, 2013). The national database and surveys are publically available; refer to the CDC website for additional information on the YRBS methods, documentation and database access (CDC, 2016). The data provided a nationally representative 
sample of the target population, enabled conducting a trends analysis, had large sample sizes to provide sufficient power, and items that adequately addressed the research questions.

\section{Measures}

The primary outcome of interest was depressed mood, suicidal thoughts and behaviors, which was defined as being present when participants answered "yes" to one or more of the following: a) "During the past 12 months, did you ever feel so sad or hopeless almost every day for two weeks or more in a row that you stopped doing some usual activities?" b) "During the past 12 months, did you ever seriously consider attempting suicide?” c) “During the past 12 months, did you make a plan about how you would attempt suicide?” d) "During the past 12 months, how many times did you actually attempt suicide?" (CDC, 2016). The outcome was analyzed as a binary categorical variable to measure the presence of any sign or symptom of depressed mood and/or suicidal behaviors, with each outcome also being analyzed in the final models. Identifying female youths exposed to physical fighting, when analyzed as a binary variable, required a response of at least " 1 time" to the following survey question: "During the past 12 months, how many times were you in a physical fight?" (CDC, 2016). The response categories for the number of times, included eight frequency categories $(0,1,2$ or 3,4 or 5,6 or 7,8 or 9,10 or 11, 12 or more). Therefore, the physical fighting frequency categories were consolidated into groups based on the distribution of responses, resulting in the four following categories: zero times, one time, two to three times and four or more times in order to evaluate the effects of more frequent exposures.

In addition to physical fighting there were four other violent behaviors (victimizing and/or aggressive in nature) that were consistently captured in the survey from 2001 through 2015 that were analyzed as binary categorical responses in the final models. The variables, 
which are referred to as "other violent events," included: carrying a weapon in the last 30 days, being absent from school due to feeling unsafe at or on the way to/from school in the last 30 days, being threatened and/or injured with a weapon on school property in the past 12 months, and having ever been physically forced to have sexual intercourse. For the 2011 to 2015 models, items to gather information on two other violent events were added to the survey and included in this study: having been bullied on school property and electronically bullied in the last 12 months. For the alternative models, the other violent events were replaced by a summation of the number of violent exposures, with the ordinal composite score ranging from zero to four for the 2001 to 2015 model, and zero to six for the 2011 to 2015 model.

Statistical Analyses

Race/ethnicity and school grade were controlled in all of the models, and a $p$-value $(p)<0.05$ was required for statistical significance. Linear and non-linear methods were used to conduct the trends analyses, and the techniques recommended by the CDC were followed (CDC, 2016b). A logistic regression analyses was conducted to test for linear, quadratic or cubic trends (CDC, 2016b). In order to identify possible inflection points when a nonlinear trend was detected, the odds ratios for each survey year were compared for significant changes (i.e. contrast statement) to the average of the other survey years. This was a planned contrast analyses for which all of the required assumptions were met, ensuring adequate control of experimental error and valid p-values. Tests for linearity were then conducted for each line segment before and after the inflection, while noting increasing or decreasing trends. In order to ensure comparability with SUDAAN (a statistical software package commonly used with complex sample survey data), analytical options for the trends analyses that are recommended for use in SAS for complex survey data were applied (Chen, 2006). Using the same trend analysis methods, a sensitivity analysis was conducted with the exposure of physical fighting requiring medical treatment, to determine if any significant changes in 
depressed mood and/or suicidal behaviors had occurred over the time period for this specific exposure. The associations between the other violent events and the outcome were measured using Pearson's correlation methods after applying the sampling weights. These results and prevalence trends for the outcome among physical fighters were evaluated to determine which, if any, of the other violent events trends mirrored the primary trends analysis results.

The final models were built to evaluate the inclusion of additional covariates into the trends analysis model when controlling for the trend type (i.e. linear, quadratic or cubic), which is necessary in order to control-out the potentially non-linear effects of time and more accurately capture the primary effects. Modified purposeful selection techniques were used to build the final multivariate logistic regression models, which used stepwise methods to evaluate covariates for inclusion in the model, both clinical and theoretical judgement based on the literature were applied. (Hosmer 1999 \& 2005). The first step in variable reduction was to test each of the other violent risk events separately to determine if they were statistically significant in the model when controlling for race, grade, survey year and physical fighting. A significance level of $p<0.05$ was required for retention, forward and backward selection techniques were then applied to determine if any of the other violent events should be excluded.

For each of the analyses, SAS® (SAS Institute Inc., Cary, NC) version 9.4 SURVEY procedures were used. Due to the three-stage cluster sample design used by the CDC to obtain a nationally representative sample of high school students, all of the analyses applied the provided sample weights, accounting for the sampling units, strata, and weights (CDC, 2016). Sampling was performed at the county level, strata accounted for urban/rural and minority composition, and weights were used due to the oversampling of Hispanic students and 
black students, while also accounting for school/student nonresponse, student sex, race/ethnicity, and grade. This study was granted protocol exempt status by the Indiana University Institutional Review Board on August 18, 2016.

\section{RESULTS}

From 2001 through 2015, the weighted sample included 57,708 female students. Within the study population the prevalence of depressed mood and/or suicidal behaviors was $43.0 \%$, and participation in a physical fighting in the past 12 months was $23.3 \%$ (Table 1). Hispanic female students had the highest prevalence of depressed mood (50.5\%), and black female students had the highest for physical fighting (33.3\%). Overall, the highest prevalence of depressed mood and/or suicidal behaviors occurred in 2015 at $45.1 \%$ and the lowest in 2009 at $39.8 \%$; physical fighting was the highest in 2005 at $28.1 \%$ and the lowest in 2015 at $16.5 \%$. The prevalence of physical fighting injuries in need of treatment and physical fights occurring on school property are also reported in Table 1.

Among female youths reporting at least one physical fight in the past 12 months, the trends analysis from 2001 to 2015 for the prevalence of depressed mood and/or suicidal behaviors did not have a statistically significant linear $(p=0.205)$ or cubic trend $(p=0.247)$ (see figure 2). A significant quadratic trend $(p<0.001)$ was present, with an inflection point in 2009 . There was a statistically significant linear decrease from 2001 to 2009 ( $p<0.001$ ), followed by a significant linear increase from 2009 to 2015 ( $p<0.001)$. Among physical fighters, the prevalence of depressed mood and/or suicidal behaviors was $65.7 \%$ in 2001 and $67.8 \%$ in 2015 versus $57.6 \%$ in 2009 , compared to $37.2 \%$ in 2001 and $40.9 \%$ in 2015 versus $34.6 \%$ in 2009 among those who were not physical fighters. For the other violent events, there was a statistically significant correlation with the outcome $(p<0.001)$, with the exception of threatened and/or injured with a weapon among physical fighters in $2015(p=0.329)$. Among physical fighters, those who also carried a weapon and/or had a history of forced 
sexual intercourse followed a similar prevalence pattern in the outcome as all physical fighters. The results for the sensitivity trends analysis for physical fighting injuries needing treatment are also shown in Figure 2.

The final models resulted in female physical fighters having a greater odds of developing depressed mood and/or suicidal behaviors than those without a history, even when controlling for other violent risk factors, race, grade and the quadratic trend for survey year (Table 2). For model 1 (2001-2015), as the frequency in the number of physical fights increased, the odds ratio for the outcome also increased. The odds of physical fighting increased by frequency: $2.02(95 \% \mathrm{CI}=[1.89,2.17])$ for one, $2.28(95 \% \mathrm{CI}=[2.07,2.52])$ for two to three, and $2.50(95 \% \mathrm{CI}=[2.15,2.92])$ for four or more fights. When the model was analyzed for each outcome separately, an increase in the odds ratios consistently corresponded with an increase in physical fighting frequency. In addition, among those with four or more fights, the odds ratios increased with the severity of the outcome, specifically, the odds for depressed mood was $2.25(95 \% \mathrm{CI}=[1.93,2.62])$, considered suicide $2.74(95 \% \mathrm{CI}=[2.36,3.18])$, planned suicide $3.00(95 \% \mathrm{CI}=[2.57,3.50])$, and attempted suicide $4.14(95 \% \mathrm{CI}=[3.47$, 4.94]). This pattern was not consistently observed in model 2 (2011 to 2015). For model 1 the highest odds ratio for planned suicide, attempted suicide and suicide attempted with injury needing treatment by a healthcare professional was among female youths with four or more physical fights, when compared to the other violence variables. This pattern was also observed in model 2 (2011 to 2015), which included bullied and electronically bullied as violent risk factors.

Given the relationship between physical fighting frequency and the outcome of depressed mood and/or suicidal behaviors, the prevalence of the other violent risk behaviors among those with the outcome by physical fighting frequency status are depicted from 2001 through 
2015 in Figure 3. During this time period, the range in prevalence of at least one other violent event by physical fighting status in the past 12 months were as follows: non-physical fighters from $25.1 \%$ (2003) to $31.3 \%$ (2013), one physical fight from $41.5 \%$ (2015) to $45.8 \%$ (2013), two to three fights from $46.2 \%$ (2011) to $55.9 \%$ (2001), four or more fights from $61.8 \%$ (2005) to $73.1 \%$ (2013), Figure 3. From 2011 to 2015 when accounting for bullying and electronic bullying, the highest prevalence of at least one other violent event occurred in 2013 among those with four or more physical fights at $87.8 \%$, followed by those with two to three fights at $74.5 \%$, then one fight (in 2015 ) at $70.4 \%$ and those with no physical fights at $56.0 \%$. Among female adolescents with a greater frequency of physical fighting in the past 12 months, there is a consistent corresponding greater prevalence of at least one other violent exposure.

The increase in the prevalence for at least one other violent event was notably steeper, approximately $10 \%$ to $20 \%$ increases, when including bullying versus the subsequent addition of electronic bullying, approximately $1 \%$ to $7 \%$ increases (Figure 3). Therefore, Table 3 depicts the changes in prevalence for the frequency of other violent events among physical fighters. The highest change in prevalence occurs for three or more other violent exposures, which is more than $10 \%$ higher each year from 2011 to 2015 when accounting for electronic bullying.

Alternative models were built to determine the odds of depressed mood and/or suicidal behaviors when other violent events were captured as a composite score, shown in Table 4. The odds ratio for the outcome is consistently higher for the composite score of other violent events when compared to physical fighting frequency, with the exception of one violent exposure and four or more physical fights for the following outcomes in model 1: considered suicide $2.42(95 \% \mathrm{CI}=[2.26,2.61])$ vs. $2.69(95 \% \mathrm{CI}=[2.34,3.09])$, planned suicide attempt 
$2.53(95 \% \mathrm{CI}=[2.34,2.74])$ vs. $2.83(95 \% \mathrm{CI}=[2.42,3.30])$, attempted suicide $2.97(95 \% \mathrm{CI}=[2.71,3.27])$ vs. $4.06(95 \% \mathrm{CI}=[3.44,4.80])$, and attempted suicide injury needed treatment $3.72(95 \% \mathrm{CI}=[3.13,4.43])$ vs. $3.99(95 \% \mathrm{CI}=[3.18,5.01])$, respectively. This is also observed in model 2, however only for the outcomes of planned suicide attempt and attempted suicide, 2.35 (95\% CI=[2.07, 2.67]) vs. $2.51(95 \% \mathrm{CI}=[1.75,3.58])$, and $3.05(95 \% \mathrm{CI}=[2.48,3.76])$ vs. $3.26(95 \% \mathrm{CI}=[2.14,4.98])$, respectively. There was a gradient increase in the odd ratio as the number of other violent events increased with the exception of five events compared to six events in model 2. Also, four or more physical fights was not a statistically significant risk factor for the overall outcome $(p=0.092)$ or depressed mood $(p=0.311)$ in model 2.

\section{DISCUSSION}

This research found that depressed mood and/or suicidal behaviors among female adolescents s who have engaged in at least one physical fight in the past 12 months have been increasing since 2009. Physical fighting remained an important risk factor across the study period, for which there was an increasing odds ratio with an increasing frequency of fights and stronger associations with the severity of the individual outcomes. This was similar to what was observed for the cumulative number of exposure to other violent events. In addition, the introduction of electronic bullying was a significant contributor to the odds of depressed mood and suicidality while also serving as an additional violent event that contributed to polyvictimization. 
Research specific to female adolescents with bidirectional violence exposure and the associated mental health outcomes are limited. Thus, this study fills an important gap in knowledge about how the prevalence of depressed mood/and or suicidal behaviors among physical fighters has changed in recent years, particularly with the introduction of electronic bullying. Suicide rates have increased from 1999 to 2014 (Curtain, 2016); however, in this study we observed an initial decline in suicide-related behaviors among female adolescents who were engaged in physical fighting. An increase was observed starting in 2009 with carrying a weapon and forced sexual intercourse contributing to the overall trend. The difference in these trends may be related to changes in the lethality of the means used to attempt suicide, given a notable increase in completed suicides by suffocation (including hanging and strangulation) among female youths and differences in the sampled populations and study methods (Curtin, 2016). Similar to other research, we found both violent victimization and aggressive behaviors to be strong risk factors for depressed mood and suicidality, a high prevalence of violent victimization among aggressors, and higher odds ratios with greater frequency of exposures or behaviors (Gower, 2013; Lereya, 2015; Satyanarayan, 2015;

Ulloa, 2016). Overall, these results contribute to how violence adversely effects youth and the means for identifying those who are at risk, which has been identified as an area of need for enabling effective trauma-related services (Donisch, 2016).

The sensitivity analysis also showed an increase in the outcome among female youths who needed an injury treated by a healthcare professional from a physical fight. In data not reported, an increase in the treatment of such injuries was observed in this population, from approximately $9 \%$ in 2009 to $12 \%$ in 2013 , unlike the numerical decrease reported for the annual rate of assault-related injuries among female adolescents treated in US emergency departments (Bell, 2016). Also, in 2015 approximately three out of every 10 female youths who needed treatment for an injury from a physical fight also reported needing treatment for a suicide attempt in the past 12 months. 
When analyzing more recent data from 2011 to 2015 and accounting for both bullying and electronically bullying, the pattern in odds ratiosfor physical fighting by frequency is not as strong and the degree of differences in the prevalence of at least one other violent risk event is not as steep; however, both were still present. Across the overall and individual outcomes for depressed mood and suicidal behaviors, the accumulation of at least two other violent events was a consistent and stronger predictor compared to any frequency of physical fighting. Even with the limited number of violent events that were consistently captured during this time period, on average the prevalence of having at least one other violent event was approximately two times greater among physical fighters than non-fighters.

When accounting for bullying and electronic bullying, nearly three out of every four physical fighters had been exposed to at least one other violent event which continued to exceed the prevalence among non-fighters. Also, electronic bullying contributed to a rise in the prevalence of three or more violent events among physical fighters. Overall, the introduction of electronic bullying as a new vehicle of violence introduces more opportunities for violence exposure putting female adolescents at even greater odds of depressed mood and/or suicidal behaviors, which also induces more susceptibility to re-victimization and an accumulation of violent events, aggressive behaviors, and other adverse outcomes (Deeds, 2007; Ruback, 2014; van der Put, 2015).

Aggressive behaviors may be serving as a means to cope with prior violence exposures and mental health symptoms, however, similar to alcohol and drugs, the perceived relief is temporary and overtime becomes more deleterious to ones health and mortality (Donisch, 2016; NCTSN, 2016). This current study focused on female high school students; however, more research in the younger age groups would be of great value given that $9^{\text {th }}$ graders are were found to have the highest prevalence of physical fighting as well as depressed mood and/or 
suicidal behaviors (Andrews, 2015). The National Child Traumatic Stress Network (NCTSN) recognizes the phenomena of complex trauma in youth that can result in self-harm and assaulting others, hence advocating for trauma-informed adolescent service practices (NCTSN, 2016). Early interventions have the potential to induce the most public health benefit, the adoption of trauma-informed practices is essential to the school environment and emergency departments, such that adolescent aggressors of violence can be managed using evidence-based methods that recognize the significant burden of past and current violent exposures and mental health sequelae (Lereya, 2015; McLoughlin, 2015; NCTSN, 2016; Sumner, 2015).

Strengths of this study include the use of a database that provided results that are generalizable to female high school students due to the robust methods of the YRBS, which provides a nationally representative sample of high school students in the U.S. Established methods for conducting a trends analysis methods were implemented in this study, with variables that were consistently collected across the study period. The validity of the questionnaires have been established, with methodological studies confirming the test-retest reliability and validity of the questionnaire, along with evaluation and institution of standard practices to ensure the accuracy of prevalence estimates for risk behaviors (Brener, 2017). Quality assurance measures are implemented to reduce reporting bias, which is essential given the sensitive nature of the questions asked and the need for anonymity;therefore, skip patterns are not used and other measures are put in place to ensure privacy (Brener, 2013; Krumpal, 2013). Multiple outcomes, violent risk factors, and frequencies were analyzed, providing epidemiological evidence in regard to changes in exposures linked to responses. 
One of the key limitations in this study was not being able to establish the sequence of events as related to violent exposures, aggressive behaviors and the outcomes, the use of cross-sectional data lacks the ability to establish cause and effect. Systematic error was possible given the study period, as interpretation and response behaviors of high school students may have changed. Several of the self-reported questions asked about the prior 12 months making recall bias or errors plausible. Given that a high-risk study population was of interest, these individuals are more likely to enter the juvenile justice system, be expelled or drop out of high school, and would thus be underrepresented in the survey, particularly, students who would have otherwise been in the higher grade levels (CDC, 2016 \& 1992; DePaoli, 2015; Donisch, 2016). There are geographical variations that attribute to the risks and outcomes of interest in this study; however, the results are representative only at the national level and cannot be extrapolated to local communities. Exposures to other violent risk events may have been underreported given the limited number of events captured by the YRBS survey. The information on perpetrating behaviors versus violence victimization were limited, due to the manner in which questions were asked; for example, perpetrators of electronic bullying were not captured and the rational for participating in a physical fight could have been related to selfdefense. Also, other variables of potential interest were not measured, such as past medical and mental health conditions, access to treatment, family-history, economic status, and changes in community and school environments during this time period (CDC, 2016 \& 1992).

With the notable decline in physical fighting among female adolescents and acknowledging the introduction of electronic bullying leaves the unanswered question whether the physical form of aggression is being replaced by electronic forms. This is important given the finding that infrequent bullying perpetration and victimization has been found to induce a greater odds for expressing both internalizing 
and externalizing behaviors (Gower, 2013). Also, since measuring all forms of violence exposure is not feasible, there is a need to determine the appropriate violence variables for measuring risk related to progression, depressed mood and suicidal outcomes, enabling the development of valid methods for collecting reliable data on violence-related victimization and perpetration.

\section{PUBLIC HEALTH IMPLICATIONS}

Considering that physical fighting is a recognizable behavior, particularly when it occurs at school or results in an injury, school administrators and health care providers may have opportunities to intervene. Also, this population is at risk of two forms of injuries in need of treatment by a healthcare professionals: injuries sustained from fighting and those by suicide attempts, providing more interactions with the healthcare system, particularly in emergency department settings (Bridge, 2015; Cunningham, 2014; Turecki, 2016). These youth also have a greater risk of entering the juvenile justice system, where their trauma-related sequela also needs to be addressed (Bohnert, 2015). Policies need to be put in place for the integration of evidence-base violence prevention practices into schools, health care settings, and juvenile justice settings, to reduce the number of exposures among youth, while also addressing gender-differences and the mental health needs related to violence (NCTSN, 2016; Ranney, 2014; Sumner, 2015). In addition, continued research on this complex issue, specifically for adolescents with bidirectional violence and polyvictimization, is essential given the disproportionately high odds ratiosfor depressed mood and suicidality in this population. 


\section{ACKNOWLEDGEMENTS:}

This research was made possible by the Fairbanks School of Public Health, and the public availability of the YRBS dataset via the CDC.

\section{HUMAN PARTICIPATION PROTECTION:}

This study was granted protocol exempt status by the Indiana University Institutional Review Board on August 18, 2016.

\section{AUTHOR CONTRIBUTIONS:}

J. Ford conceptualized the present study, wrote the study protocol and first draft of the article, with the advice of T. Zollinger, D. Nelson, J. O’Neil, J. Zhang, and G. Steele. D. Nelson advised on statistical methods and J. Ford conducted the analyses. T. Zollinger was responsible for oversight of this research. All authors contributed to the drafting and editing of the article. 


\section{REFERENCES}

Andrews, A. R., Jobe-Shields, L., López, C. M., Metzger, I. W., de Arellano, M. A., Saunders, B., \& Kilpatrick, D. G. (2015). Polyvictimization, income, and ethnic differences in trauma-related mental health during adolescence. Social psychiatry and psychiatric epidemiology, 50(8), 1223-1234.

Bell, T. M., Qiao, N., Jenkins, P. C., Siedlecki, C. B., \& Fecher, A. M. (2016). Trends in Emergency Department Visits for Nonfatal Violence-Related Injuries Among Adolescents in the United States, 2009-2013. Journal of Adolescent Health, 58(5), 573-575.

Bohnert, K. M., Walton, M. A., Ranney, M., Bonar, E. E., Blow, F. C., Zimmerman, M. A., ... \& Cunningham, R. M. (2015). Understanding the service needs of assault-injured, drug-using youth presenting for care in an urban Emergency Department. Addictive behaviors, 41, 97-105.

Boots, D., \& Wareham, J. (2009). An exploration of DSM-oriented scales in the prediction of criminal offending among urban American youths. Criminal Justice and Behavior, 36(8), 840-860. doi:10.1177/0093854809337714.

Brener, N. D., Kann, L., Shanklin, S., Kinchen, S., Eaton, D. K., Hawkins, J., \& Flint, K. H. (2013). Methodology of the youth risk behavior surveillance system-2013. MMWR Recomm Rep, 62(1), 1-20. Retrieved from CDC website (May 19, 2017): https://www.cdc.gov/mmwr/pdf/rr/rr6201.pdf

CDC - Center for Disease Control and Prevention (2016). Adolescent and School Health Youth Risk Behavior Surveillance System (YRBSS) Methods. Retrieved from CDC website (May 19, 2017): https://www.cdc.gov/healthyyouth/data/yrbs/methods.htm

Chen, X. (2006). Surveylogistic regression: Some SAS ${ }^{\circledR}$ and SUDAAN® comparisons. Proceedings of NESUG (North East SAS Users Group Conference). Retrieved from NESUG website (April 3, 2017): http://www.lexjansen.com/nesug/nesug06/po/po12.pdf

Cunningham, R. M., Ranney, M., Newton, M., Woodhull, W., Zimmerman, M., \& Walton, M. A. (2014). Characteristics of youth seeking emergency care for assault injuries. Pediatrics, 133(1), e96-e105.

Curtin, S. C., Warner, M., \& Hedegaard, H. (2016). Increase in suicide in the United States, 1999-2014. NCHS data brief, $241,1-8$.

Deeds, B. G., Lagrange, R., \& Simoni-Wastile, L. (2007). Understanding trends in youth violence: The role of gender, victimization, and depression. Journal of Adolescent Health, 40, S15-S16. 
DePaoli, J. L., Fox, J. H., Ingram, E. S., Maushard, M., Bridgeland, J. M., \& Balfanz, R. (2015). Building a Grad Nation: Progress and Challenge in Ending the High School Dropout Epidemic. Annual Update 2015. Civic Enterprises.

Donisch, K., Bray, C., \& Gewirtz, A. (2016). Child welfare, juvenile justice, mental health, and education providers' conceptualizations of trauma-informed practice. Child maltreatment, 21(2), 125-134.

Giletta, M., Hastings, P. D., Rudolph, K. D., Bauer, D. J., Nock, M. K., \& Prinstein, M. J. (2016). Suicide ideation among high-risk adolescent females: Examining the interplay between parasympathetic regulation and friendship support. Development and psychopathology, 1-15.

Gladden RM, Vivolo-Kantor AM, Hamburger ME, Lumpkin CD. (2013). Bullying Surveillance Among Youths: Uniform Definitions for Public Health and Recommended Data Elements, Version 1.0. Atlanta, GA; National Center for Injury Prevention and Control, Centers for Disease Control and Prevention and U.S. Department of Education. Retrieved from CDC website (May 19, 2017): http://www.cdc.gov/violenceprevention/pdf/bullying-definitions-final-a.pdf

Goldman-Mellor, S. J., Caspi, A., Harrington, H., Hogan, S., Nada-Raja, S., Poulton, R., \& Moffitt, T. E. (2014). Suicide attempt in young people: a signal for long-term health care and social needs. JAMA psychiatry, 71(2), 119-127.

Goldston, D. B., Daniel, S. S., Erkanli, A., Heilbron, N., Doyle, O., Weller, B., ... \& Faulkner, M. (2015). Suicide attempts in a longitudinal sample of adolescents followed through adulthood: Evidence of escalation. Journal of consulting and clinical psychology, 83(2), 253.

Gower, A. L., \& Borowsky, I. W. (2013). Associations between frequency of bullying involvement and adjustment in adolescence. Academic pediatrics, 13(3), 214-221.

Hawton, K., i Comabella, C. C., Haw, C., \& Saunders, K. (2013). Risk factors for suicide in individuals with depression: a systematic review. Journal of affective disorders, 147(1), 17-28.

Herrman, J. W., \& Silverstein, J. (2012). Girls and violence: a review of the literature. Journal of community health nursing, 29(2), 63-74.

Hosmer DW, \& Lemeshow S. (1999). Applied Survival Analysis: Regression Modeling of Time to Event Data (pp.132-153). New York: Wiley.

Hosmer, D. W., \& Lemeshow, S. (2005). Applied logistic regression (pp. 31-46, 91-142). John Wiley \& Sons, Inc. 
Kann, L. (2016). Youth Risk Behavior Surveillance—United States, 2015. MMWR. Surveillance Summaries. 2016; 65. Retrieved from CDC website (May 19, 2017): https://www.cdc.gov/mmwr/volumes/65/ss/ss6506a1.htm

Lenhart, A. (2012). Teens, smartphones \& texting. Pew Internet \& American Life Project.

Lereya, S. T., Copeland, W. E., Zammit, S., \& Wolke, D. (2015). Bully/victims: a longitudinal, population-based cohort study of their mental health. European child \& adolescent psychiatry, 24(12), 1461-1471.

Madden, M., Lenhart, A., Duggan, M., Cortesi, S., \& Gasser, U. (2013). Teens and technology 2013. Retrieved from Pew Internet and American Life Project website (May 19, 2017): http://www.pewinternet.org/2013/03/13/teens-and-technology-2013/

McLoughlin, A. B., Gould, M. S., \& Malone, K. M. (2015). Global trends in teenage suicide: 2003-2014. Quarterly Journal of Medicine (QJM), hev026.

National Child Traumatic Stress Network (NCTSN). (2016). Creating trauma informed systems. Retrieved from NCTSN Website (May 19, 2017): http://www.nctsn.org/

National Institute of Health (NIH) (2011). National Institutes of Health Violence Against Women Research Report, Fiscal Year 2011. Retrieved from NIH Website (May 19, 2017): http://orwh.od.nih.gov/resources/policyreports/pdf/VAW-NIH-Report-2011.pdf

Ranney, M. L., Locci, N., Adams, E. J., Betz, M., Burmeister, D. B., Corbin, T., ... \& North, C. (2014). Gender-specific Research on Mental Illness in the Emergency Department: Current Knowledge and Future Directions. Academic Emergency Medicine, 21(12), $1395-1402$

Resko, S. M., Reddock, E. C., Ranney, M. L., Epstein-Ngo, Q., Mountain, S. K., Zimmerman, M. A., ... \& Walton, M. A. (2016). Reasons for fighting among violent female adolescents: A qualitative investigation from an urban, midwestern community. Social work in public health, 31(3), 99-112.

Ruback, R. B., Clark, V. A., \& Warner, C. (2014). Why Are crime victims at risk of being victimized again? Substance use, depression, and offending as mediators of the victimization-revictimization link. Journal of interpersonal violence, 29(1), 157-185.

Satyanarayana, V. A., Chandra, P. S., \& Vaddiparti, K. (2015). Mental health consequences of violence against women and girls. Current opinion in psychiatry, 28(5), 350-356.

Sumner, S. A., Mercy, J. A., Dahlberg, L. L., Hillis, S. D., Klevens, J., \& Houry, D. (2015). Violence in the United States: status, challenges, and opportunities. Journal of American Medical Association (JAMA), 314(5), 478-488. 
Swahn, M. H., Bossarte, R. M., Palmier, J. B., Yao, H., \& Van Dulmen, M. H. (2013). Psychosocial characteristics associated with frequent physical fighting: findings from the 2009 National Youth Risk Behavior Survey. Injury prevention, 19(2), 143-146.

Turecki, G., \& Brent, D. A. (2016). Suicide and suicidal behaviour. The Lancet, 387(10024), 1227-1239.

Ulloa, E. C., \& Hammett, J. F. (2016). The Effect of Gender and Perpetrator-Victim Role on Mental Health Outcomes and Risk Behaviors Associated With Intimate Partner Violence. Journal of interpersonal violence, 31(7), 1184-1207.

van der Put, C. E., Lanctôt, N., De Ruiter, C., \& Van Vugt, E. (2015). Child maltreatment among boy and girl probationers: Does type of maltreatment make a difference in offending behavior and psychosocial problems?. Child abuse \& neglect, 46, 142-151.

Wilkins, N., Tsao, B., Hertz, M., Davis, R., Klevens, J. (2014). Connecting the Dots: An Overview of the Links Among Multiple Forms of Violence. Atlanta, GA: National Center for Injury Prevention and Control, Centers for Disease Control and Prevention Oakland, CA: Prevention Institute. Retrieved from CDC Website (May 19, 2017): https://www.cdc.gov/violenceprevention/pdf/connecting_the_dots-a.pdf

Ybarra, M. L., Mitchell, K. J., \& Korchmaros, J. D. (2011). National trends in exposure to and experiences of violence on the Internet among children. Pediatrics, 128(6), e1376-e1386. 
FIGURE 1. Conceptual Framework for Adolescent Mental Health Trends and the Relationship with Violence

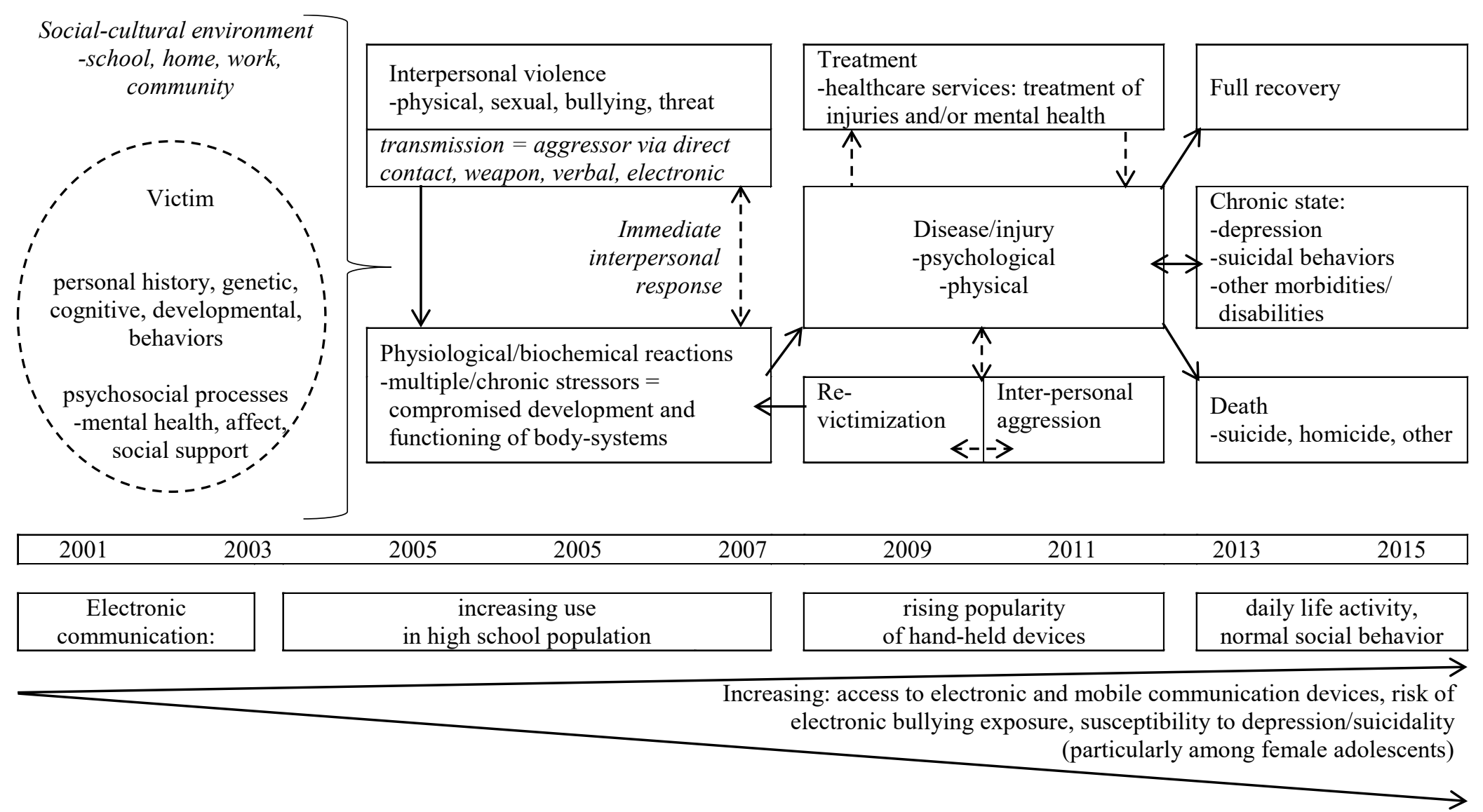


Table 1. Demographics, Prevalence of Depressed Mood and/or Suicidal Behaviors and Physical Fighting among Female Adolescents, 2001 through 2015 (YRBS)

\begin{tabular}{|c|c|c|c|c|c|c|c|c|c|c|c|}
\hline $\begin{array}{l}\text { Prevalence } \\
\text { of Outcome/ } \\
\text { Exposure } \\
\text { by Year }\end{array}$ & $\begin{array}{c}\text { Depressed } \\
\text { Mood/Suicidal } \\
\text { Behaviors }\end{array}$ & $\begin{array}{c}\text { Depressed } \\
\text { Mood }\end{array}$ & $\begin{array}{l}\text { Consider } \\
\text { Suicide }\end{array}$ & $\begin{array}{c}\text { Plan } \\
\text { Suicide }\end{array}$ & $\begin{array}{l}\text { Attempt } \\
\text { Suicide }\end{array}$ & $\begin{array}{l}\text { Attempt } \\
\text { Treated }\end{array}$ & $\begin{array}{l}\text { Physical } \\
\text { Fighting } \\
\text { Total }\end{array}$ & $\begin{array}{l}\text { Fighting } \\
\text { Injury } \\
\text { Treated }\end{array}$ & $\begin{array}{l}\text { Physical } \\
\text { Fighting at } \\
\text { School }\end{array}$ & \multicolumn{2}{|c|}{ Total } \\
\hline & $\%$ & $\%$ & $\%$ & $\%$ & $\%$ & $\%$ & $\%$ & $\%$ & $\%$ & \multicolumn{2}{|c|}{$\mathrm{n}$} \\
\hline 2001 & 43.9 & 34.5 & 23.6 & 17.7 & 11.2 & 3.1 & 23.9 & 2.9 & 7.2 & \multicolumn{2}{|c|}{6953.0} \\
\hline 2003 & 45.0 & 35.5 & 21.3 & 18.9 & 11.5 & 3.2 & 25.1 & 2.6 & 8.0 & \multicolumn{2}{|c|}{7361.0} \\
\hline 2005 & 43.4 & 36.7 & 21.8 & 16.2 & 10.8 & 2.9 & 28.1 & 2.4 & 8.8 & \multicolumn{2}{|c|}{6858.0} \\
\hline 2007 & 41.5 & 35.8 & 18.7 & 13.4 & 9.3 & 2.4 & 26.5 & 2.9 & 8.5 & \multicolumn{2}{|c|}{6942.0} \\
\hline 2009 & 39.8 & 33.9 & 17.4 & 13.2 & 8.1 & 2.3 & 22.9 & 2.2 & 6.7 & \multicolumn{2}{|c|}{7816.0} \\
\hline 2011 & 41.3 & 35.9 & 19.3 & 14.9 & 9.8 & 2.9 & 24.4 & 2.6 & 7.8 & \multicolumn{2}{|c|}{7446.0} \\
\hline 2013 & 44.3 & 39.1 & 22.4 & 16.9 & 10.6 & 3.6 & 19.2 & 2.4 & 5.6 & \multicolumn{2}{|c|}{6780.0} \\
\hline 2015 & 45.1 & 39.8 & 23.4 & 19.4 & 11.6 & 3.7 & 16.5 & 1.8 & 5.0 & \multicolumn{2}{|c|}{7551.0} \\
\hline by Race & $\%$ & $\%$ & $\%$ & $\%$ & $\%$ & $\%$ & $\%$ & $\%$ & $\%$ & $\mathrm{n}$ & $\%$ \\
\hline White & 40.3 & 34.0 & 20.4 & 15.6 & 8.8 & 2.5 & 19.7 & 1.7 & 5.1 & 33778 & 59.3 \\
\hline Black & 41.6 & 34.6 & 17.5 & 13.5 & 9.5 & 2.7 & 33.3 & 3.9 & 12.6 & 8130 & 14.3 \\
\hline Hispanic & 50.5 & 44.0 & 23.4 & 18.4 & 14.3 & 4.3 & 27.3 & 3.7 & 9.8 & 10252 & 18.0 \\
\hline Other & 47.7 & 39.1 & 25.4 & 21.0 & 14.9 & 4.0 & 23.3 & 3.1 & 7.1 & 4829 & 8.5 \\
\hline by Grade & $\%$ & $\%$ & $\%$ & $\%$ & $\%$ & $\%$ & $\%$ & $\%$ & $\%$ & $\mathrm{n}$ & $\%$ \\
\hline 9th & 44.9 & 37.5 & 23.0 & 17.8 & 12.9 & 3.7 & 29.3 & 3.1 & 10.5 & 16167 & 28.1 \\
\hline 10 th & 44.1 & 37.1 & 22.6 & 18.0 & 11.5 & 3.2 & 24.3 & 2.5 & 7.2 & 14878 & 25.9 \\
\hline 11 th & 43.1 & 36.6 & 20.0 & 15.5 & 9.3 & 2.6 & 20.6 & 2.1 & 5.6 & 13641 & 23.7 \\
\hline 12th & 39.2 & 33.8 & 17.3 & 13.1 & 6.6 & 2.1 & 17.3 & 1.9 & 4.4 & 12835 & 22.3 \\
\hline Total & 43.0 & 36.4 & 20.9 & 16.3 & 10.3 & 3.0 & 23.3 & 2.5 & 7.2 & 57708 & 100.0 \\
\hline
\end{tabular}

Note: Depressed Mood and/or Suicidal Behaviors accounts for at least one positive response to having a depressed mood, considering, planning or attempting suicide in the past 12 months. Physical Fighting is a positive response to at least one physical fight in the past 12 months. Weighted values are reported. 

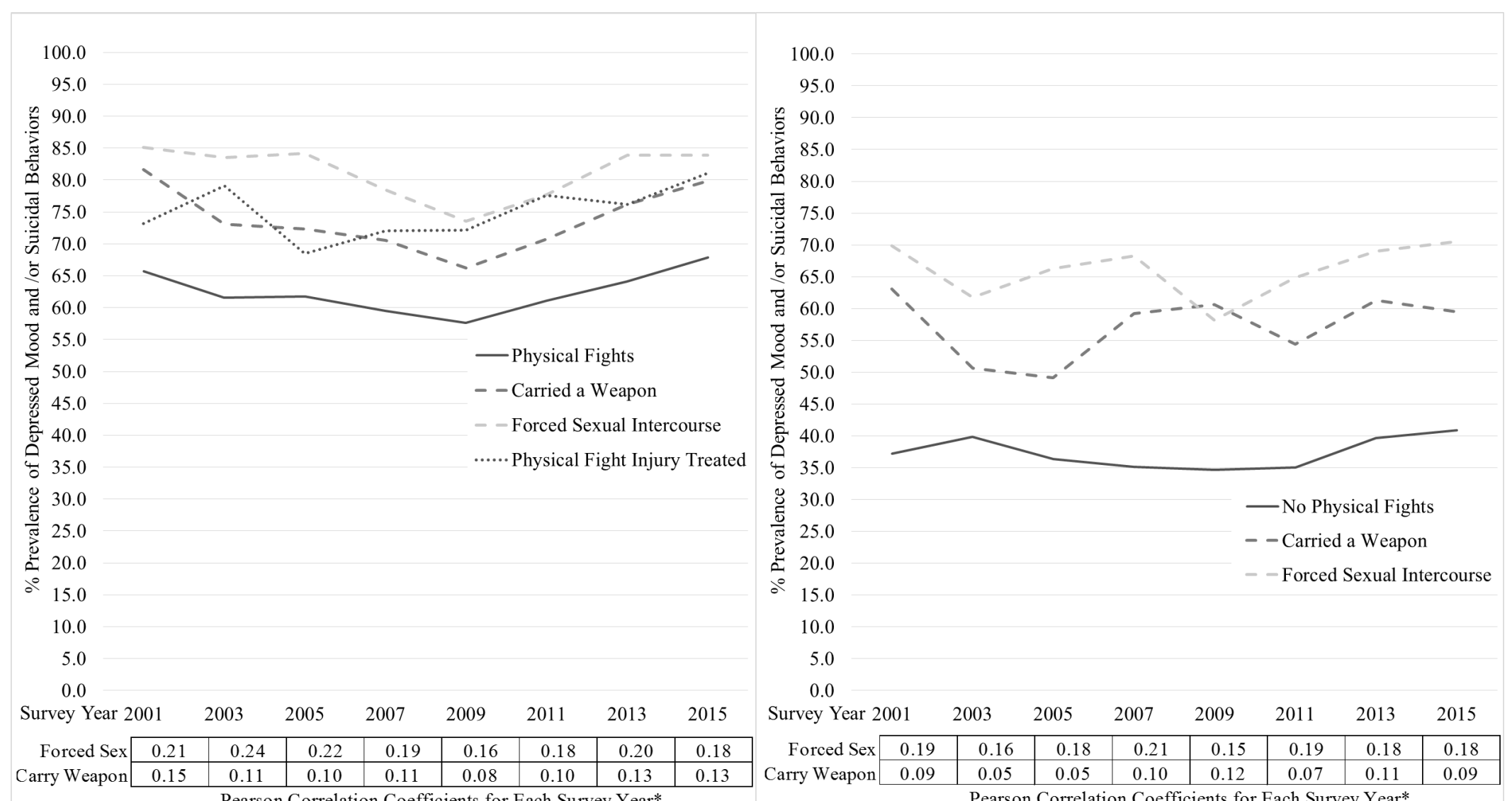

Figure 2. YRBS Trends Analysis 2001-2015: Depressed Mood and/or Suicidal Behaviors Among Female Adolescents Exposed to Physical Fighting vs. Non-Physical Fighters

Depressed Mood and/or Suicidal Behaviors: Significant quadratic trend, 2009 is statistically significantly different than the average for the other years, $p<0.001$; years post 2009 are also significantly different (2011: $p=0.007,2013: \mathrm{p}=0.024,2015: p=0.007)$. 2001-2009 is a significant linear decrease $(p<0.001), 2009-2015$ is a significant linear increase $(p<0.001)$. Treated Injury from Physical Fight: Significant quadratic trend, 2009 is statistically significantly different than the average of the other years $(p<0.001), 2011$ is also significantly different $(p=0.039)$. 2001-2009 is a significant linear decrease $(p<0.001), 2009-2015$ is a significant linear increase $(p=0.001)$. Other violent events were significantly correlated with the outcome $(p<0.001)$, except being threatened or injured with a weapon among physical fighters in $2015(p=0.329)$. Among physical fighters only carried a weapon and forced sexual intercourse followed a similar pattern. 
Table 2. Final Models: Odds Ratio for Depressed Mood and/or Suicidal Behaviors, Physical Fighting and Other Violent Behaviors among Female Adolescents (YRBS, 2001-2015)

\begin{tabular}{|c|c|c|c|c|c|c|}
\hline Model 1: & $\begin{array}{l}\text { Depressed/ } \\
\text { Suicidality }\end{array}$ & $\begin{array}{l}\text { Depressed } \\
\text { Mood }\end{array}$ & $\begin{array}{l}\text { Consider } \\
\text { Suicide }\end{array}$ & Plan Suicide & $\begin{array}{l}\text { Attempt } \\
\text { Suicide }\end{array}$ & $\begin{array}{c}\text { Suicide Attempt } \\
\text { Injury Treated }\end{array}$ \\
\hline 2001-2015* & $\begin{array}{c}\mathrm{OR} \\
95 \% \mathrm{CI}\end{array}$ & $\begin{array}{c}\text { OR } \\
95 \% \mathrm{CI}\end{array}$ & $\begin{array}{c}\mathrm{OR} \\
95 \% \mathrm{CI}\end{array}$ & $\begin{array}{c}\text { OR } \\
95 \% \mathrm{CI}\end{array}$ & $\begin{array}{c}\mathrm{OR} \\
95 \% \mathrm{CI}\end{array}$ & $\begin{array}{c}\text { OR } \\
95 \% \mathrm{CI}\end{array}$ \\
\hline Physical fighting: & 2.02 & 1.96 & 2.00 & 1.76 & 2.34 & 2.21 \\
\hline 1x/12 months & {$[1.89, \quad 2.17]$} & {$[1.83,2.11]$} & {$[1.84,2.16]$} & {$[1.60,1.93]$} & {$[2.09,2.63]$} & {$[1.76, \quad 2.77]$} \\
\hline Physical fighting: & 2.28 & 2.14 & 2.23 & 1.97 & 2.70 & 2.78 \\
\hline $2-3 \mathrm{x} / 12$ months & {$[2.07,2.52]$} & {$[1.95,2.34]$} & {$[2.02,2.46]$} & {$[1.75,2.23]$} & {$[2.39,3.05]$} & {$[2.19,3.52]$} \\
\hline Physical fighting: & 2.50 & 2.25 & 2.74 & 3.00 & 4.14 & 4.28 \\
\hline $4+x / 12$ months & {$[2.15,2.92]$} & {$[1.93,2.62]$} & {$[2.36,3.18]$} & {$[2.57,3.50]$} & {$[3.47,4.94]$} & {$[3.33,5.48]$} \\
\hline $\begin{array}{l}\text { Carried a weapon } \\
\text { (last } 30 \text { days) }\end{array}$ & $\begin{array}{c}1.75 \\
{[1.60, \quad 1.92]}\end{array}$ & $\begin{array}{c}1.59 \\
{[1.43, \quad 1.76]}\end{array}$ & $\begin{array}{c}1.77 \\
{[1.61, \quad 1.95]}\end{array}$ & $\begin{array}{c}1.84 \\
{[1.66, \quad 2.04]}\end{array}$ & $\begin{array}{c}2.04 \\
{[1.81, \quad 2.30]}\end{array}$ & $\begin{array}{c}2.23 \\
{[1.85, \quad 2.70]}\end{array}$ \\
\hline $\begin{array}{l}\text { School absence, } \\
\text { unsafe }(\geq 1 / 30 \text { days })\end{array}$ & $\begin{array}{c}2.46 \\
{[2.18, \quad 2.78]}\end{array}$ & $\begin{array}{c}2.66 \\
{[2.37, \quad 2.98]}\end{array}$ & $\begin{array}{c}1.68 \\
{[1.50, \quad 1.90]}\end{array}$ & $\begin{array}{c}1.62 \\
{[1.43, \quad 1.84]}\end{array}$ & $\begin{array}{c}2.03 \\
{\left[\begin{array}{ll}1.75, & 2.34]\end{array}\right.}\end{array}$ & $\begin{array}{c}2.24 \\
{[1.77, \quad 2.85]}\end{array}$ \\
\hline $\begin{array}{l}\text { Threatened/injured } \\
\text { with weapon }\end{array}$ & $\begin{array}{c}2.02 \\
{[1.77, \quad 2.30]}\end{array}$ & $\begin{array}{c}1.83 \\
{[1.63, \quad 2.06]}\end{array}$ & $\begin{array}{c}1.75 \\
{[1.56, \quad 1.97]}\end{array}$ & 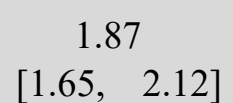 & $\begin{array}{c}1.90 \\
{[1.65, \quad 2.18]}\end{array}$ & $\begin{array}{c}1.67 \\
{[1.34, \quad 2.07]}\end{array}$ \\
\hline $\begin{array}{l}\text { Forced intercourse/ } \\
\text { sex (lifetime) }\end{array}$ & $\begin{array}{c}3.20 \\
{[2.96, \quad 3.50]}\end{array}$ & $\begin{array}{c}2.87 \\
{[2.66, \quad 3.10]}\end{array}$ & $\begin{array}{c}2.96 \\
{[2.75, \quad 3.19]}\end{array}$ & $\begin{array}{c}2.85 \\
{[2.61, \quad 3.10]}\end{array}$ & $\begin{array}{c}3.38 \\
{[3.05, \quad 3.75]}\end{array}$ & $\begin{array}{c}3.97 \\
{[3.34, \quad 4.71]}\end{array}$ \\
\hline
\end{tabular}

Model controlled for grade, race and quadratic trend for survey year. Reference groups for physical fighting is non-fighters, reference group for other violent events is no exposures.

*Variables in 2001-2015 models were statistically significant $(p<.010)$ 
Table 2. (Continued) Final Models: Odds Ratio for Depressed Mood and/or Suicidal Behaviors, Physical Fighting and Other Violent Behaviors among Female Adolescents (YRBS, 2001-2015)

\begin{tabular}{|c|c|c|c|c|c|c|}
\hline Model 2: & $\begin{array}{l}\text { Depressed/ } \\
\text { Suicidality }\end{array}$ & $\begin{array}{l}\text { Depressed } \\
\text { Mood }\end{array}$ & $\begin{array}{l}\text { Consider } \\
\text { Suicide }\end{array}$ & Plan Suicide & $\begin{array}{l}\text { Attempt } \\
\text { Suicide }\end{array}$ & $\begin{array}{l}\text { Suicide Attempt } \\
\text { Injury Treated }\end{array}$ \\
\hline $2011-2015^{* *}$ & $\begin{array}{c}\text { OR } \\
95 \% \mathrm{CI}\end{array}$ & $\begin{array}{c}\text { OR } \\
95 \% \mathrm{CI}\end{array}$ & $\begin{array}{c}\text { OR } \\
95 \% \mathrm{CI}\end{array}$ & $\begin{array}{c}\text { OR } \\
95 \% \mathrm{CI}\end{array}$ & $\begin{array}{c}\text { OR } \\
95 \% \mathrm{CI}\end{array}$ & $\begin{array}{c}\text { OR } \\
95 \% \mathrm{CI}\end{array}$ \\
\hline Physical fighting: & 1.90 & 1.78 & 1.72 & 1.54 & 2.29 & 2.17 \\
\hline $1 \mathrm{x} / 12$ months & {$[1.68,2.15]$} & {$[1.57,2.01]$} & {$[1.49,1.99]$} & {$[1.30,1.83]$} & {$[1.90, \quad 2.77]$} & {$[1.52,3.11]$} \\
\hline Physical fighting: & 2.21 & 2.03 & 2.05 & 1.90 & 2.82 & 2.60 \\
\hline $2-3 x / 12$ months & {$[1.86,2.62]$} & {$[1.69, \quad 2.43]$} & {$[1.73,2.44]$} & {$[1.56,2.31]$} & {$\left[\begin{array}{ll}2.27 & 3.51\end{array}\right]$} & {$[1.78, \quad 3.80]$} \\
\hline Physical fighting: & 1.98 & 1.71 & 2.01 & 2.78 & 3.37 & 4.24 \\
\hline $4+\mathrm{x} / 12$ months & {$\left[\begin{array}{ll}1.47 & 2.68\end{array}\right]$} & {$[1.25, \quad 2.33]$} & {$[1.53,2.66]$} & {$[2.12,3.65]$} & {$[2.39,4.74]$} & {$[2.75,6.52]$} \\
\hline Carried a weapon & 1.85 & 1.58 & 1.90 & 1.85 & 2.10 & 1.67 \\
\hline (last 30 days) & {$[1.57,2.17]$} & {$[1.35,1.85]$} & {$[1.60, \quad 2.27]$} & {$[1.56,2.20]$} & {$[1.75, \quad 2.52]$} & {$[1.22, \quad 2.28]$} \\
\hline School absence, & 2.24 & 2.42 & 1.41 & 1.41 & 1.95 & 2.16 \\
\hline unsafe ( $\geq 1 / 30$ days $)$ & {$[1.87,2.69]$} & {$[2.03,2.88]$} & {$[1.17,1.71]$} & {$[1.13,1.76]$} & {$[1.60, \quad 2.39]$} & {$[1.55,3.00]$} \\
\hline Threatened/Injured & 1.29 & 1.18 & 1.23 & 1.29 & 1.56 & 1.53 \\
\hline with Weapon & {$[1.03,1.63]$} & {$[0.95,1.48]$} & {$[0.98,1.55]$} & {$[1.04,1.60]$} & {$[1.23,1.99]$} & {$[1.09, \quad 2.15]$} \\
\hline Forced intercourse/ & 2.78 & 2.46 & 2.70 & 2.62 & 3.10 & 3.34 \\
\hline sex (Lifetime) & {$[2.41, \quad 3.20]$} & {$[2.14,2.82]$} & {$[2.36, \quad 3.08]$} & {$[2.27, \quad 3.02]$} & {$[2.56, \quad 3.77]$} & {$[2.50,4.47]$} \\
\hline Physically bullied & 1.91 & 1.73 & 2.08 & 2.00 & 1.68 & 1.43 \\
\hline at school & {$[1.72, \quad 2.12]$} & {$[1.55,1.92]$} & {$[1.83,2.35]$} & {$[1.80, \quad 2.23]$} & {$[1.43,1.97]$} & {$[1.12, \quad 1.84]$} \\
\hline Electronically & 2.42 & 2.38 & 2.11 & 1.85 & 2.05 & 2.40 \\
\hline bullied & {$[2.17, \quad 2.70]$} & {$[2.13,2.67]$} & {$[1.87,2.36]$} & {$[1.62, \quad 2.12]$} & {$[1.72, \quad 2.45]$} & {$[1.79, \quad 3.21]$} \\
\hline
\end{tabular}

**Variables in 2011-2015 were statistically significant ( $\mathrm{p}<0.050)$, except threatened/injured with a weapon for depressed mood $(p=0.140)$ and consider suicide $(p=0.075)$. Reference groups for physical fighting is non-fighters, reference group for other violent events is no exposures. YRBS began collecting data on bullied at school beginning in 2009, and electronic bullying in 2011. 


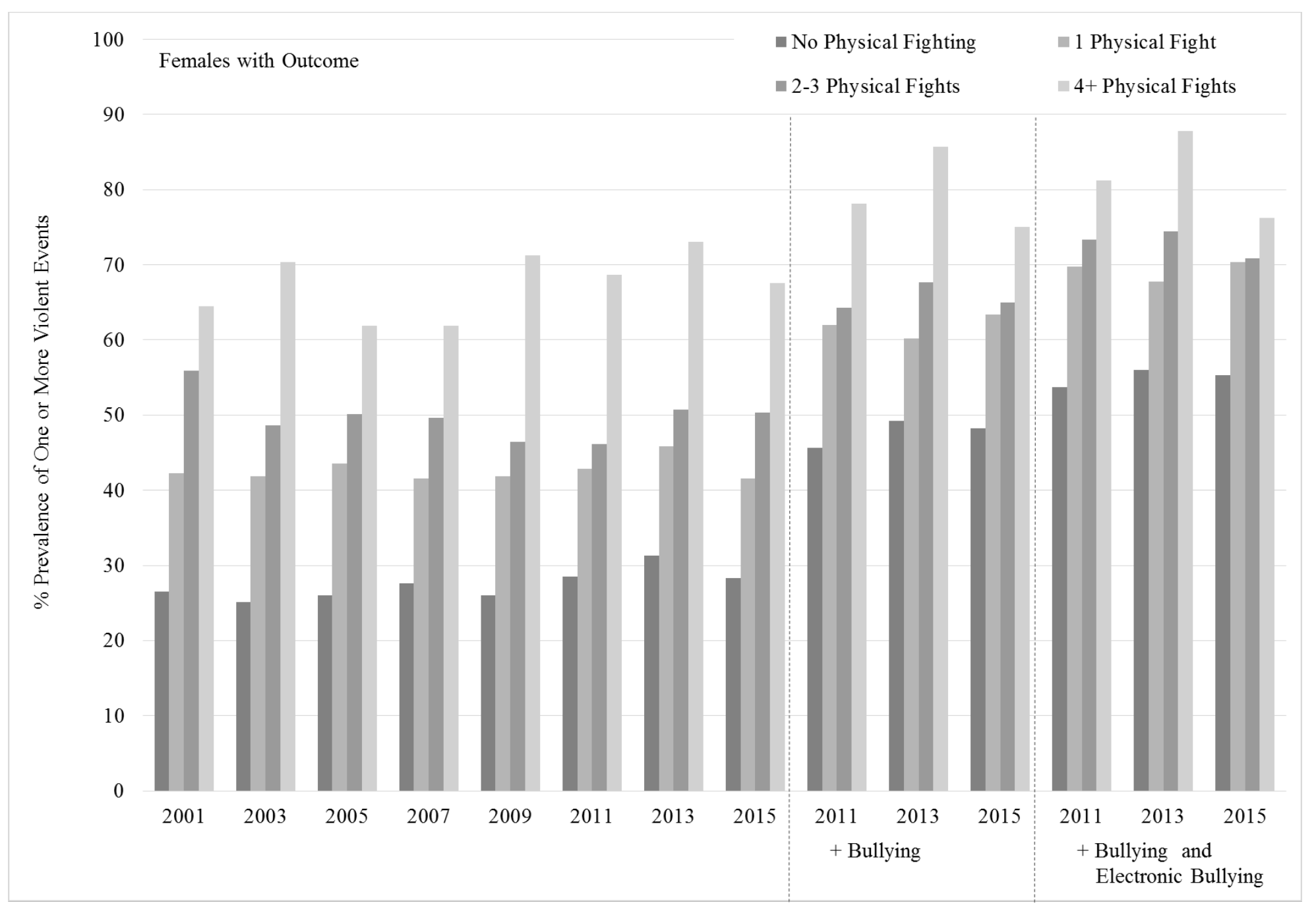

Figure 3. Prevalence of One or More Violent Events among Female Adolescents with Depressed Mood and/or Suicidal Behaviors by Physical Fighting Status in the Past 12 months

Violent risk behaviors are from Table 2 Final Model, at least one positive response to a violent risk behavior or exposure was required. * 2011-2015 data included exposures to bullying and electronic bullying. 
Table 3. Physical Fighters with Depressed Mood and/or Suicidal Behaviors, Number of Other Violent Exposures (YRBS, 2011-2015)

\begin{tabular}{lcccc}
\hline \multicolumn{2}{c}{$\begin{array}{c}\text { Prevalence of Other } \\
\text { Violent Events }\end{array}$} & & & \\
\hline \# of Other & 0 & 50.0 & 47.0 & 51.1 \\
Violent Events: & 1 & 32.3 & 28.4 & 29.5 \\
& 2 & 11.9 & 15.9 & 12.7 \\
& $3+$ & 5.8 & 8.7 & 6.7 \\
including & 0 & 33.5 & 32.1 & 34.1 \\
bullied & 1 & 36.2 & 31.1 & 30.4 \\
& 2 & 18.8 & 17.6 & 20.8 \\
& $3+$ & 11.5 & 19.2 & 14.6 \\
also including & 0 & 26.4 & 25.9 & 28.5 \\
electronically & 1 & 28.7 & 25.6 & 21.5 \\
bullied & 2 & 22.7 & 19.1 & 23.4 \\
& $3+$ & 22.2 & 29.4 & 26.6 \\
\hline
\end{tabular}

Other violent events included: carrying a weapon, absence from school at least 1 day due to feeling unsafe, threatened/injured with a weapon, and forced sexual intercourse. YRBS began collecting data on being bullied in 2009 and on electronically bullied in 2011 . 
Table 4. Alternative Models: Odds Ratio for Depressed Mood and/or Suicidal Behaviors, Physical Fighting and Other Violent Events by Frequency among Female Adolescents (YRBS, 2001-2015)

\begin{tabular}{|c|c|c|c|c|c|c|}
\hline Model 1: & $\begin{array}{l}\text { Depressed/ } \\
\text { Suicidality }\end{array}$ & $\begin{array}{l}\text { Depressed } \\
\text { Mood }\end{array}$ & $\begin{array}{l}\text { Consider } \\
\text { Suicide }\end{array}$ & Plan Suicide & Attempt Suicide & $\begin{array}{l}\text { Suicide Attempt } \\
\text { Injury Treated }\end{array}$ \\
\hline 2001-2015* & $\begin{array}{c}\mathrm{OR} \\
95 \% \mathrm{CI}\end{array}$ & $\begin{array}{c}\text { OR } \\
95 \% \mathrm{CI}\end{array}$ & $\begin{array}{c}\text { OR } \\
95 \% \mathrm{CI}\end{array}$ & $\begin{array}{c}\text { OR } \\
95 \% \mathrm{CI}\end{array}$ & $\begin{array}{c}\text { OR } \\
95 \% \mathrm{CI}\end{array}$ & $\begin{array}{c}\text { OR } \\
95 \% \mathrm{CI}\end{array}$ \\
\hline Physical fighting: & 1.99 & 1.93 & 1.95 & 1.65 & 2.27 & 2.00 \\
\hline $1 \mathrm{x} / 12$ months & {$[1.86,2.14]$} & {$[1.80, \quad 2.07]$} & {$[1.80, \quad 2.11]$} & {$[1.48,1.83]$} & {$[2.02, \quad 2.54]$} & {$[1.61,2.78]$} \\
\hline Physical fighting: & 2.18 & 2.05 & 2.16 & 1.82 & 2.61 & 2.54 \\
\hline $2-3 x / 12$ months & {$[1.98,2.14]$} & {$[1.87,2.25]$} & {$[1.95,2.38]$} & {$[1.61,2.07]$} & {$[2.30, \quad 2.96]$} & {$[2.00,3.23]$} \\
\hline Physical fighting: & 2.39 & 2.13 & 2.69 & 2.83 & 4.06 & 3.99 \\
\hline $4+\mathrm{x} / 12$ months & {$[2.06,2.77]$} & {$[1.84,2.45]$} & {$[2.34,3.09]$} & {$[2.42,3.30]$} & {$[3.44,4.80]$} & {$[3.18,5.01]$} \\
\hline 1 Violent event & 2.69 & 2.59 & 2.42 & 2.53 & 2.97 & 3.72 \\
\hline & {$[2.52, \quad 2.88]$} & {$[2.42, \quad 2.76]$} & {$[2.26, \quad 2.61]$} & {$[2.34,2.74]$} & {$[2.71,3.27]$} & {$[3.13,4.43]$} \\
\hline 2 Violent events & 5.45 & 4.71 & 4.62 & 4.56 & 5.60 & 7.43 \\
\hline & {$[4.77,6.22]$} & {$[4.12, \quad 5.37]$} & {$[4.12, \quad 5.18]$} & {$[4.08,5.11]$} & {$[4.94,6.35]$} & {$[6.10,9.05]$} \\
\hline 3 Violent events & 7.30 & 5.92 & 5.84 & 6.61 & 9.82 & 13.03 \\
\hline & {$[5.35,9.95]$} & {$[4.55,7.69]$} & {$[4.72, \quad 7.22]$} & {$[5.38, \quad 8.12]$} & {$[7.54,12.77]$} & {$[9.89,17.17]$} \\
\hline 4 Violent events & $\begin{array}{c}7.79 \\
{[3.64, \quad 16.68]}\end{array}$ & $\begin{array}{c}6.20 \\
{[3.52,10.93]}\end{array}$ & $\begin{array}{c}7.12 \\
{[4.44,11.41]}\end{array}$ & $\begin{array}{c}8.03 \\
{[5.07, \quad 12.70]}\end{array}$ & $\begin{array}{c}21.58 \\
{[13.06, \quad 35.65]}\end{array}$ & $\begin{array}{c}32.34 \\
{[20.97, \quad 49.87]}\end{array}$ \\
\hline
\end{tabular}

Reference groups for physical fighting is non-fighters, reference group for violent events is no violent event exposures.

Model controlled for grade, race and quadratic trend for survey year. Other violent events included: carrying a weapon, absence from school at least one day due to feeling unsafe, threatened/injured with a weapon, and forced sexual intercourse.

*Variables in 2001-2015 models were statistically significant $(p<0.001)$. 
Table 4. (Continued) Alternative Models: Odds Ratio for Depressed Mood and/or Suicidal Behaviors, Physical Fighting and Other Violent Events by Frequency among Female Adolescents (YRBS, 2001-2015)

\begin{tabular}{|c|c|c|c|c|c|c|}
\hline \multirow{2}{*}{$\frac{\text { Model 2: }}{2011-2015^{* *}}$} & $\begin{array}{l}\text { Depressed/ } \\
\text { Suicidality }\end{array}$ & $\begin{array}{l}\text { Depressed } \\
\text { Mood }\end{array}$ & $\begin{array}{l}\text { Consider } \\
\text { Suicide }\end{array}$ & Plan Suicide & Attempt Suicide & $\begin{array}{l}\text { Suicide Attempt } \\
\text { Injury Treated }\end{array}$ \\
\hline & $\begin{array}{c}\text { OR } \\
95 \% \mathrm{CI}\end{array}$ & $\begin{array}{c}\text { OR } \\
95 \% \mathrm{CI}\end{array}$ & $\begin{array}{c}\text { OR } \\
95 \% \mathrm{CI}\end{array}$ & $\begin{array}{c}\text { OR } \\
95 \% \mathrm{CI}\end{array}$ & $\begin{array}{c}\text { OR } \\
95 \% \mathrm{CI}\end{array}$ & $\begin{array}{c}\text { OR } \\
95 \% \mathrm{CI}\end{array}$ \\
\hline \multirow{2}{*}{$\begin{array}{l}\text { Physical fighting: } \\
1 \mathrm{x} / 12 \text { months }\end{array}$} & 2.03 & 1.75 & 1.82 & 1.65 & 2.43 & 1.45 \\
\hline & {$[1.69, \quad 2.42]$} & {$[1.47, \quad 2.07]$} & {$[1.53,2.16]$} & {$[1.35,2.00]$} & {$[1.96, \quad 3.03]$} & {$[1.06,1.99]$} \\
\hline \multirow{2}{*}{$\begin{array}{l}\text { Physical fighting: } \\
2-3 x / 12 \text { months }\end{array}$} & 2.07 & 1.96 & 1.89 & 1.80 & 2.81 & 1.45 \\
\hline & {$[1.60, \quad 2.68]$} & {$[1.50, \quad 2.55]$} & {$[1.47, \quad 2.43]$} & {$[1.41, \quad 2.31]$} & {$\left[\begin{array}{ll}2.06 & 3.82\end{array}\right]$} & {$[1.03,2.04]$} \\
\hline \multirow{2}{*}{$\begin{array}{l}\text { Physical fighting: } \\
4+\mathrm{x} / 12 \text { months }\end{array}$} & 1.38 & 1.24 & 1.71 & 2.51 & 3.26 & 2.24 \\
\hline & {$[0.95,2.02]$} & {$[0.82, \quad 1.86]$} & {$[1.22, \quad 2.39]$} & {$[1.75,3.58]$} & {$[2.14,4.98]$} & {$[1.56,3.22]$} \\
\hline \multirow{2}{*}{1 Violent event } & 2.50 & 2.30 & 2.69 & 2.35 & 3.05 & 2.97 \\
\hline & {$[2.22, \quad 2.82]$} & {$[2.02, \quad 2.62]$} & {$[2.40,3.02]$} & {$[2.07,2.67]$} & {$[2.48, \quad 3.76]$} & {$[2.06,4.28]$} \\
\hline \multirow{2}{*}{2 Violent events } & 4.56 & 4.33 & 4.75 & 3.98 & 4.91 & 8.61 \\
\hline & {$[3.93,5.29]$} & {$[3.76,4.99]$} & {$[4.03,5.60]$} & {$[3.28,4.82]$} & {$[3.73,6.45]$} & {$[6.34,11.70]$} \\
\hline \multirow{2}{*}{3 Violent events } & 10.55 & 7.93 & 8.92 & 7.54 & 8.98 & 15.72 \\
\hline & {$[8.02,13.87]$} & {$[6.43,9.78]$} & {$[6.77, \quad 11.74]$} & {$[5.69,9.98]$} & {$[6.63,12.17]$} & {$[10.45, \quad 23.64]$} \\
\hline \multirow{2}{*}{4 Violent events } & 11.76 & 9.28 & 11.91 & 8.92 & 16.24 & 25.46 \\
\hline & {$[7.51,18.41]$} & {$[6.10,14.13]$} & {$[8.12,17.48]$} & {$[6.13,12.97]$} & {$[10.98, \quad 24.03]$} & {$[17.22, \quad 37.64]$} \\
\hline \multirow{2}{*}{5 Violent events } & 18.79 & 14.00 & 20.02 & 22.77 & 46.29 & 64.52 \\
\hline & {$[5.04, \quad 70.04]$} & {$[4.83,40.62]$} & {$[8.38,47.82]$} & {$[10.55,49.11]$} & {$[23.65,90.58]$} & {$[34.36,121.13]$} \\
\hline \multirow{2}{*}{6 Violent events } & 12.00 & 15.67 & 17.70 & 16.15 & 28.49 & 101.39 \\
\hline & {$[2.72, \quad 53.04]$} & {$[3.48,70.64]$} & {$[5.92, \quad 52.91]$} & {$[6.05,43.13]$} & {$[10.60, \quad 76.59]$} & {$[42.75,240.49]$} \\
\hline
\end{tabular}

**Variables in 2011-2015 were statistically significant $(\mathrm{p}<0.050)$, except physical fighting $4+$ times for depressed/suicidality $(p=0.092)$ and depressed mood only $(p=0.311)$. YRBS began collecting data on being bullied at school beginning in 2009, and electronic bullying in 2011, which were included as potential violent events in this model. 